\title{
What Impairs Balance in Ankylosing Spondylitis? Posture or Disease Activity?
}

\author{
Osman Hakan GÜNDÜZ, ${ }^{1}$ Emel Ece ÖZCAN-EKŞİ, ${ }^{2}$ Esra GİRAY, ${ }^{1}$ İlker YAĞCI ${ }^{1}$ \\ ${ }^{1}$ Department of Physical Medicine and Rehabilitation, Medical Faculty of Marmara University, İstanbul, Turkey \\ ${ }^{2}$ Department of Physical Medicine and Rehabilitation, Antalya Ataturk State Hospital, Antalya, Turkey
}

\begin{abstract}
Objectives: This study aims to compare ankylosing spondylitis (AS) patients with healthy subjects in terms of posture and balance, and to identify the factors correlated with balance in AS.

Patients and methods: Thirty patients (17 males, 13 females; mean age $41.7 \pm 7.7$ years; range 31 to 57 years) with AS and 33 healthy subjects ( 18 males, 15 females; mean age $41.3 \pm 7.0$ years; range 26 to 56 years) were included in the study. Participants were assessed in terms of posture and balance. Posture was assessed using tragus-wall distance, modified Schober's test, and chest expansion. Balance was assessed using device-assisted balance tests. Pain (visual analog scale) and disease activity (Bath Ankylosing Spondylitis Disease Activity Index) were assessed only in AS patients.

Results: Ankylosing spondylitis patients walked more slowly when compared to healthy subjects $(p=0.002)$. As the modified Schober's test was restricted, AS patients had greater step width in tandem walk and higher sway velocity on foam base $(r=-0.418 p=0.022 ; r=-0.473 p=0.008)$. Neither Bath Ankylosing Spondylitis Disease Activity Index nor visual analog scale was correlated with balance.

Conclusion: Static and dynamic balance are impaired in AS patients when compared to healthy subjects. Restricted mobility of the spine and advanced kyphosis impaired balance, while pain and disease activity had no correlations with balance.

Keywords: Ankylosing spondylitis; dynamic balance; posture; static balance.
\end{abstract}

Ankylosing spondylitis (AS) is a chronic and inflammatory disease, which mainly affects the axial skeleton and leads to morning stiffness in the spine. ${ }^{1}$ Progression of the morning stiffness due to chronic inflammation may cause postural changes. Consequently, AS patients may end up having flattened lumbar lordosis and advanced thoracic kyphosis.

Neutral posture is the anatomical alignment of spinal curves, which is coordinated in response to changes in center of gravity (COG). The coordination of posture with the COG is called "balance". Subjects with postural changes were expected to have a displaced COG, which is difficult to control for AS patients, since they usually have rigid lower limbs. ${ }^{2}$ It has been shown that AS patients required more energy to control their COG. ${ }^{3-5}$ Impaired control of COG results in balance disorders and falls. Falls were reported as the leading cause of spinal fractures. It has been reported that spinal fractures resulted in higher morbidity and mortality in AS patients when compared to those in healthy subjects. ${ }^{6}$

Further disabilities and falls may be avoided by understanding the factors affecting balance in AS patients. Previously, only static or dynamic balance were assessed in AS patients. ${ }^{5-7}$ However, we were unable to detect any trial in the literature assessing both static and dynamic balance in AS patients. Therefore, factors affecting balance in AS patients are still unclear. 
In this study, we aimed to compare AS patients with healthy subjects in terms of posture and balance, and to identify the factors correlated with balance in AS.

\section{PATIENTS AND METHODS}

The study included 30 patients with AS (17 males, 13 females; mean age $41.7 \pm 7.7$ years; range 31 to 57 years), who were admitted to the rheumatology outpatient clinic of Marmara University School of Medicine Department of Physical Medicine and Rehabilitation between February 2014 and September 2014 and 33 healthy subjects (18 males, 15 females; mean age $41.3 \pm 7.0$ years; range 26 to 56 years) as the control group. The institutional review board approval was obtained from the Ethics Committee of Marmara University Medical School (approval date: 01/12/2011, project number: 09.2011.070). Oral and written informed consents were obtained from all participants. The study was conducted in accordance with the principles of the Declaration of Helsinki. Patients were excluded if they met any of the following criteria: Age $>70$ years, history of orthopedic disorders, spine or lower limb surgery, cardiovascular disorders, neurologic disorders, psychiatric disorders, cognitive impairment, visual and auditory deficits.

Firstly, participants were assessed in terms of posture and balance. Then, AS patients were assessed in terms of symptom duration, pain, and disease activity. Each balance test was performed three times. The test results were the average of the values of three trials.

Participants were assessed in the afternoon to eliminate the effects of morning stiffness.

\section{1) Postural assessment}

Tragus-wall distance (TWD), modified Schober's test (MST), and chest expansion were measured for postural assessment.

Tragus-wall distance: ${ }^{8}$ The distance between the tragus and wall was measured while the subject was standing with his/her heels touching against the wall.

Modified Schober's test: ${ }^{2}$ With the subject in an upright posture, the posterior superior iliac spines were palpated. The low back of the subject was marked $10 \mathrm{~cm}$ above and $5 \mathrm{~cm}$ below that point. Then, the subject was requested to touch the floor as well as he/she could. The distance between two marks was measured.

Chest expansion: ${ }^{9}$ The subject was requested to do full expiration three times. Then, the circumference of thorax was measured with a tape measure, placed at the level of the fourth rib. After that, subject was requested to do full inspiration, with arms abducted. The difference between these two measurements was recorded.

Symptom duration (months), pain (visual analog scale; 0-10 cm), and disease activity (Bath Ankylosing Spondylitis Disease Activity Index) were also assessed in subjects with AS.

\section{2) Balance assessment}

Participants were assessed in terms of balance by using Neurocom Balance Master System ${ }^{\circledR}$ (NeuroCom. International, Inc., Clackamas, Orlando, USA) device-assisted balance tests as in the following:

a) Static balance tests

- Weight bearing squat test: This test revealed percentage of body weight borne by each foot while standing (knees extended, $0^{\circ}$ flexed) and squatting with $30^{\circ}, 60^{\circ}$, and $90^{\circ}$ flexed knees. The differences between percentages of body weight on the right and left foot depicted static balance impairment.

- Modified clinical tests of sensory interaction on balance: The subject stood on a firm base with eyes opened and closed. Then, the test was repeated on a foam base. This was performed three times. The mean values of sway velocity (degree/second) and COG alignment (degree) were assessed. This test indicates whether visual system or proprioception helped to maintain balance (Figure 1).

b) Dynamic balance tests

- Walk across test: The subjects walked on a firm base of support as usual and got off the base of support. This test was repeated three times. The step length $(\mathrm{cm})$, step width $(\mathrm{cm})$, speed $(\mathrm{cm} / \mathrm{second})$, and step length symmetry (\%) were measured. 


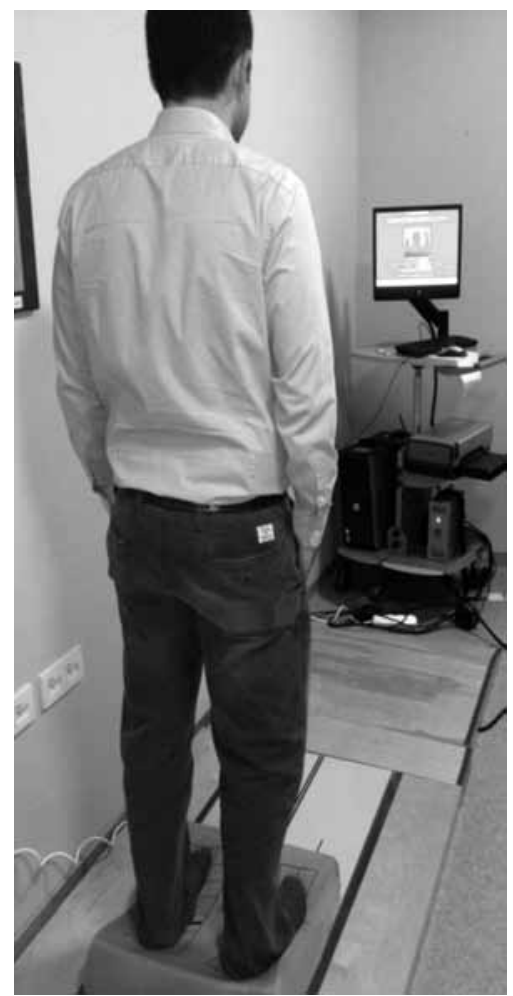

Figure 1. Standing on foam base.

- Tandem walk test: The subjects performed a tandem walk and waited at the end of the base of support. This test was repeated three times. The step width $(\mathrm{cm})$, speed (cm/second), and the end sway (degree/ second) were assessed (Figure 2).

- Step and quick turn test: The subjects took their left steps first and then their right steps forward. Then, they turned $180^{\circ}$ back without taking their feet off the base of support. This test was performed three times for each side; the mean values of turning time to left and right (second) and turning sway (degree) were assessed.

\section{Statistical analysis}

IBM SPSS for Windows version 22.0 software (IBM Corporation, Armonk, NY, USA) was used for statistical analysis. Independent samples t-test was used for intergroup comparison of parameters with normal distribution and quantitative data. Pearson correlation was used for correlation of the quantitative data.

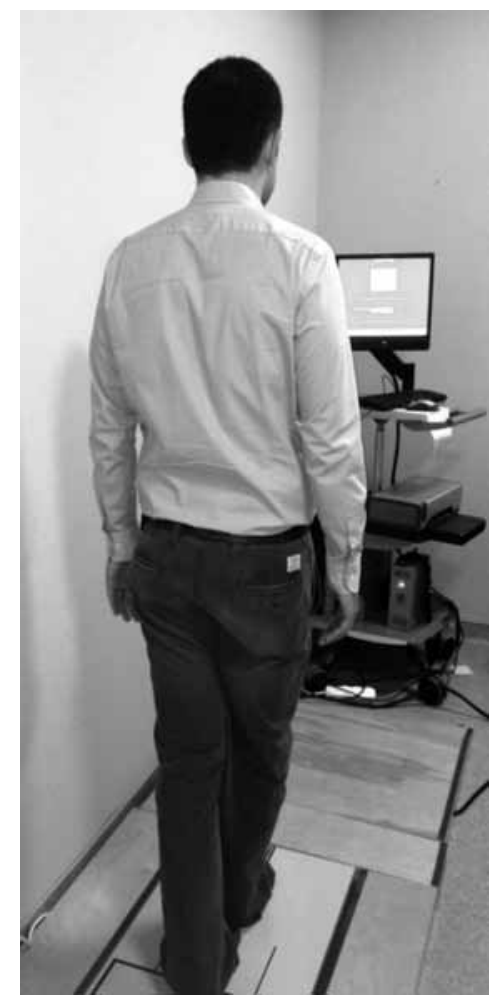

Figure 2. Tandem walk test.

\section{RESULTS}

All participants completed the device-assisted balance tests. The groups were similar in terms of age and body mass index (Table 1). In AS patients; mean duration of disease and mean Bath Ankylosing Spondylitis Disease Activity Index were $8.6 \pm 8.4$ years and $4.7 \pm 2.6$, respectively. In AS patients; means of visual analog scale, TWD, and MST were $5.9 \pm 2.1 \mathrm{~cm}, 17.7 \pm 5.6 \mathrm{~cm}$, and $18.6 \pm 2.8 \mathrm{~cm}$, respectively.

Postural assessment reveled that AS patients had significantly decreased MST and chest expansion measurements than the healthy subjects (Table 2). Balance assessment showed that groups were similar in weight bearing squat test (Table 2). However, AS patients had more sway while standing on firm base when compared to the healthy subjects when eyes closed $(p=0.03)$. In walk across test, AS patients widened and shortened their steps while walking when compared to the healthy subjects ( $p=0.026$; $\mathrm{p}=0.010$ ). AS patients walked more slowly in walk across and tandem walk tests than the healthy subjects $(p=0.002 ; p=0.015)$ (Table 2). 
Table 1. Demographic data of groups

\begin{tabular}{lcccc}
\hline & AS group & & Control group & \\
\cline { 2 - 3 } & Mean $\pm \mathrm{SD}$ & & Mean $\pm \mathrm{SD}$ & $p$ \\
\hline Age $($ year $)$ & $41.7 \pm 7.7$ & & $41.3 \pm 7.0$ & 0.818 \\
Height $(\mathrm{cm})$ & $170.3 \pm 9.5$ & & $166.1 \pm 9.7$ & 0.083 \\
Weight $(\mathrm{kg})$ & $78.0 \pm 13.4$ & & $75.4 \pm 12.8$ & 0.436 \\
BMI $\left(\mathrm{kg} / \mathrm{m}^{2}\right)$ & $26.8 \pm 3.9$ & & $27.4 \pm 4.4$ & 0.619 \\
\hline AS: Ankylosing spondylitis; SD: Standard deviation; BMI: Body mass index.
\end{tabular}

Ankylosing spondylitis patients had restricted MST as they had increased TWD, restricted chest expansion, and prolonged duration of disease $(\mathrm{r}=-0.439 \mathrm{p}=0.015 ; \mathrm{r}=0.389 \mathrm{p}=0.033 ; \mathrm{r}=-0.421$ $p=0.021$ ). As MST restricted, AS patients had increased sway while standing on foam base when eyes opened and closed $(r=-0.473 p=0.008$; $r=-0.558 \mathrm{p}=0.001$ ). As TWD increased, AS patients had increased sway while standing on foam base when eyes opened $(r=0.379 p=0.039)$. As MST restricted and TWD increased, AS patients widened their steps in tandem walk test $(r=-0.418 p=0.022 ; r=0.433 p=0.017)$. As the chest expansion decreased, AS patients completed the step and quick turn tests in longer time with increased sway $(r=-0.458 \mathrm{p}=0.011$; $\mathrm{r}=-0.423 \mathrm{p}=0.020$ ). Neither Bath Ankylosing Spondylitis Disease Activity Index nor visual analog scale showed significant correlations with balance and posture parameters (Table 3).

\section{DISCUSSION}

In this study, we aimed to determine whether AS patients had worse static and dynamic balance than healthy subjects. Our second aim was to determine the factors associated with balance impairment in AS patients. For these purposes, AS patients and age-matched healthy subjects were assessed using postural measurements and device-assisted balance tests. Then; the associations of posture, pain, and disease activity with balance were assessed.

In our study, AS patients could not maintain their static balance as well as the healthy subjects could while standing on firm base when eyes closed. It has been reported that AS patients had proprioceptive deficits when compared to healthy subjects. ${ }^{7}$ Since proprioception becomes

Table 2. Posture and balance parameters used for assessment of groups

\begin{tabular}{lccc}
\hline & AS group & Control group \\
\cline { 2 - 4 } & Mean \pm SD & Mean \pm SD & $p$ \\
\hline Modified Schober's test (cm) & $18.6 \pm 2.9$ & $22.3 \pm 3.3$ & $0.001^{*}$ \\
Tragus-wall distance (cm) & $17.8 \pm 5.7$ & $14.5 \pm 2.3$ & $0.02^{*}$ \\
Chest expansion (cm) & $4.6 \pm 1.5$ & $8.0 \pm 1.6$ & $0.001^{*}$ \\
Weight bearing squat test - $0^{\circ}$ (\% of body weight) & $9.1 \pm 7.6$ & $10.2 \pm 7.5$ & 0.584 \\
Weight bearing squat test - 30 (\% of body weight) & $7.7 \pm 7.5$ & $7.2 \pm 5.5$ & 0.728 \\
Weight bearing squat test - 60 (\% of body weight) & $7.8 \pm 5.9$ & $10.1 \pm 8.5$ & 0.210 \\
Weight bearing squat test - 90 (\% of body weight) & $7.2 \pm 6.6$ & $8.9 \pm 7.5$ & 0.350 \\
SVEO (degree/sec) & $0.1 \pm 0.1$ & $0.2 \pm 0.2$ & 0.083 \\
SVEC (degree/sec) & $0.1 \pm 0.1$ & $0.1 \pm 0.8$ & $0.030^{*}$ \\
SVFEO (degree/sec) & $0.5 \pm 0.3$ & $0.5 \pm 0.2$ & 0.757 \\
SVFEC (degree/sec) & $1.1 \pm 0.4$ & $1.1 \pm 0.4$ & 0.992 \\
Step width, walk across (cm) & $18.9 \pm 3.4$ & $17.1 \pm 2.6$ & $0.026^{*}$ \\
Step length, walk across (cm) & $46.2 \pm 9.0$ & $52.5 \pm 9.8$ & $0.010^{*}$ \\
Speed, walk across (cm/sec) & $53.1 \pm 13.1$ & $63.3 \pm 12.3$ & $0.002^{*}$ \\
Step length symmetry, walk across (\%) & $12.4 \pm 12.0$ & $12.2 \pm 16.0$ & 0.956 \\
Step width, tandem walk (cm) & $6.4 \pm 1.2$ & $6.8 \pm 0.9$ & 0.158 \\
Speed, tandem walk (cm/sec) & $21.5 \pm 5.4$ & $24.8 \pm 5.0$ & $0.015^{*}$ \\
End sway, tandem walk (degree/sec) & $4.4 \pm 1.5$ & $4.6 \pm 1.4$ & 0.475 \\
Turn time, left, SQT (sec) & $1.6 \pm 0.6$ & $1.5 \pm 1.2$ & 0.743 \\
Turn time, right, SQT (sec) & $1.5 \pm 0.9$ & $1.5 \pm 1.0$ & 0.879 \\
Turn time, mean, SQT (sec) & $1.5 \pm 0.7$ & $1.5 \pm 1.0$ & 0.924 \\
Turn sway, left, SQT (degree) & $27.1 \pm 18.4$ & $25.4 \pm 6.7$ & 0.632 \\
Turn sway, right, SQT (degree) & $24.1 \pm 9.4$ & $27.2 \pm 6.3$ & 0.138 \\
Turn sway, mean, SQT (degree) & $25.6 \pm 10.7$ & $26.3 \pm 6.0$ & 0.762 \\
\hline AS: Ankylosing spondylitis; SD: Standard deviation; * p<0.05; SVEO: Sway velocity in standing on firm base, eyes opened; SVEC: Sway velocity in standing \\
on firm base, eyes closed; SVFEO: Sway velocity in standing on foam base, eyes opened; SVFEC: Sway velocity in standing on foam base, eyes closed; \\
SQT: Step and quick turn test. & & & \\
\hline
\end{tabular}




\begin{tabular}{|c|c|c|c|c|c|c|}
\hline & MST & TWD & Chest expansion & Duration & BASDAI & VAS \\
\hline SVEO (degree/sec) & $\begin{array}{c}-0.473 \\
0.008^{*}\end{array}$ & $\begin{array}{l}0.379 \\
0.039^{*}\end{array}$ & $\begin{array}{l}0.042 \\
0.824\end{array}$ & $\begin{array}{r}-0.007 \\
0.970\end{array}$ & $\begin{array}{r}-0.007 \\
0.691\end{array}$ & $\begin{array}{l}0.003 \\
0.989\end{array}$ \\
\hline SVEC (degree/sec) & $\begin{array}{c}-0.558 \\
0.001^{*}\end{array}$ & $\begin{array}{l}0.221 \\
0.240\end{array}$ & $\begin{array}{r}-0.217 \\
0.249\end{array}$ & $\begin{array}{l}0.110 \\
0.562\end{array}$ & $\begin{array}{r}-0.282 \\
0.138\end{array}$ & $\begin{array}{r}-0.076 \\
0.691\end{array}$ \\
\hline Tandem walk-step width (cm) & $\begin{array}{c}-0.418 \\
0.022^{*}\end{array}$ & $\begin{array}{l}0.433 \\
0.017^{*}\end{array}$ & $\begin{array}{r}-0.146 \\
0.441\end{array}$ & $\begin{array}{l}0.443 \\
0.014\end{array}$ & $\begin{array}{r}-0.041 \\
0.833\end{array}$ & $\begin{array}{l}0.089 \\
0.642\end{array}$ \\
\hline SQT-turn time (sec) & $\begin{array}{r}-0.147 \\
0.438\end{array}$ & $\begin{array}{r}-0.006 \\
0.977\end{array}$ & $\begin{array}{l}-0.458 \\
0.011^{*}\end{array}$ & $\begin{array}{r}-0.018 \\
0.927\end{array}$ & $\begin{array}{r}-0.037 \\
0.847\end{array}$ & $\begin{array}{r}-0.283 \\
0.130\end{array}$ \\
\hline SQT-turn sway (sec) & $\begin{array}{r}-0.021 \\
0.912\end{array}$ & $\begin{array}{l}0.150 \\
0.428\end{array}$ & $\begin{array}{c}-0.423 \\
0.020^{*}\end{array}$ & $\begin{array}{r}-0.190 \\
0.314\end{array}$ & $\begin{array}{l}0.243 \\
0.203\end{array}$ & $\begin{array}{c}-0.114 \\
0.550\end{array}$ \\
\hline
\end{tabular}

MST: Modified Schober's test; TWD: Tragus-wall distance; BASDAI: Bath Ankylosing Spondylitis Disease Activity Index; VAS: Visual analog scale; SVEO: Sway velocity in standing on firm base, eyes opened; SVEC: Sway velocity in standing on firm base, eyes closed; SQT: Step and quick turn test; * $\mathrm{p}<0.05$.

more important when eyes closed, proprioceptive deficits might have impaired static balance in AS group.

Furthermore, we observed that AS patients had worse dynamic balance while walking when compared to healthy subjects. AS patients widened steps and walked slowly to compensate their poor dynamic balance.

As duration of AS prolonged, mobility of the lumbar spine was restricted in AS patients. Patients with restricted mobility of the lumbar spine also had advanced kyphosis, and advanced kyphosis was associated with restricted chest expansion. It has been shown that advanced kyphosis was associated with duration of the disease. ${ }^{10}$ Our results showed that mobility of the lumbar spine was restricted even in the first decade of AS and affected the thoracic kyphosis. Thus, maintaining mobility of the lumbar spine should be the goal of rehabilitation in the early stages of AS.

As the kyphosis advanced and mobility of the lumbar spine was restricted, AS patients had more difficulty maintaining their balance while standing on foam. This impairment in static balance can be explained by the impaired gaze stability due to advanced kyphosis and forward head posture in AS patients, as reported previously. ${ }^{11}$ AS patients also widened their steps in tandem walk as a compensatory mechanism to maintain their balance on narrow base of support. It has been shown that advanced kyphosis caused a forward and downward shift in COG ${ }^{12}$ impaired postural stability, ${ }^{10}$ and dynamic balance ${ }^{5}$ in AS patients. Our results indicated that advanced kyphosis and restricted mobility of the spine impaired both dynamic and static balance in AS patients. In another study conducted by Adam et al., ${ }^{13} 30$ patients with AS were compared to 20 healthy controls in terms of postural stability and dynamic balance via computerized interactive balance system. They reported that there was no difference between healthy controls and AS patients in terms of balance and general stability parameters and they found a negative correlation between Schober's test and general stability scores.

In our study, restricted chest expansion was associated with difficulty in maintaining balance in step and quick turn in AS patients. To the best of our knowledge, the association of chest expansion with balance has not been shown yet. We also observed that restricted chest expansion was associated with restricted mobility of the lumbar spine and advanced kyphosis.

Neither pain nor disease activity had significant correlations with balance or posture in AS patients. Aydog et al. ${ }^{5}$ reported that patients with increased disease activity had advanced kyphosis. It has been shown that disease activity had no significant correlations with balance in AS. 5,7,10

Our study showed that restricted mobility of the lumbar spine and advanced kyphosis impaired both dynamic and static balance in subjects with AS. It has been reported that restricted mobility of the lumbar spine, hip, knee, and ankle involvement impaired postural control and increased the risk of fall. ${ }^{14,15}$ Falls were suggested as the most common causes of spinal fractures 
which resulted in higher morbidity and mortality in subjects with AS when compared to those without AS. ${ }^{6}$ Thus, postural assessment is crucial to predict and prevent balance disorders and falls in AS patients.

There is no specific tool to assess balance in AS patients. In the previously published studies assessing balance in AS patients, Berg Balance Scale, force plate, ${ }^{4}$ Biodex Stability System, ${ }^{5}$ and magnometry ${ }^{7}$ were used to assess dynamic or static balance in AS.

We assessed both dynamic and static balance in subjects with AS and healthy subjects by using device-assisted balance tests. Supporting the literature, results of our study showed that AS patients had impaired balance and postural changes were detected to be associated with impaired balance of AS patients.

We recognize our limitations. The deviceassisted balance tests were not compared to other validated balance assessment tools and there were limited number of subjects. On the other hand, our control group was age, sex, height, and weight matched to the AS group.

In conclusion, restricted mobility of the lumbar spine and advanced kyphosis impaired both dynamic and static balance, while restricted chest expansion impaired only the dynamic balance in AS. Postural assessment and rehabilitation should be an inevitable part of follow-up to prevent balance disorders and related falls in AS patients. Further studies are required to detect a specific and validated tool to assess balance in AS patients.

\section{Acknowledgements}

We would like to thank Firat Ulutatar, MD, for taking photographs.

\section{Declaration of conflicting interests}

The authors declared no conflicts of interest with respect to the authorship and/or publication of this article.

\section{Funding}

The authors received no financial support for the research and/or authorship of this article.

\section{REFERENCES}

1. Sieper J, Rudwaleit M, Khan MA, Braun J. Concepts and epidemiology of spondyloarthritis. Best Pract Res Clin Rheumatol 2006;20:401-17.

2. Khan MA. Rheumatology. In: Klippel JH, Dieppe PA, editors. St Louis: Mosby; 1994. p. 10-1.

3. Gall V. Exercise in the spondyloarthropathies. Arthritis Care Res 1994;7:215-20.

4. Bot SD, Caspers M, Van Royen BJ, Toussaint HM, Kingma I. Biomechanical analysis of posture in patients with spinal kyphosis due to ankylosing spondylitis: a pilot study. Rheumatology (Oxford) 1999;38:441-3.

5. Aydog E, Depedibi R, Bal A, Eksioglu E, Unlü E, Cakci A. Dynamic postural balance in ankylosing spondylitis patients. Rheumatology (Oxford) 2006;45:445-8.

6. Westerveld LA, van Bemmel JC, Dhert WJ, Oner FC, Verlaan JJ. Clinical outcome after traumatic spinal fractures in patients with ankylosing spinal disorders compared with control patients. Spine J 2014;14:729-40.

7. Murray HC, Elliott C, Barton SE, Murray A. Do patients with ankylosing spondylitis have poorer balance than normal subjects? Rheumatology (Oxford) 2000;39:497-500.

8. Russel AS. Ankylosing spondylitis: clinical features. In: Klippel JH, Dieppe PA, editors. Rheumatology. St Louis: Mosby; 1994. p. 1-2.

9. Moll JM, Wright V. The pattern of chest and spinal mobility in ankylosing spondylitis. An objective clinical study of 106 patients. Rheumatol Rehabil 1973;12:115-34.

10. Durmus B, Altay Z, Ersoy Y, Baysal O, Dogan E. Postural stability in patients with ankylosing spondylitis. Disabil Rehabil 2010;32:1156-62.

11. Pompeu JE, Romano RS, Pompeu SM, Lima SM. Static and dynamic balance in subjects with ankylosing spondylitis: literature review. Rev Bras Reumatol 2012;52:409-16.

12. Wing AM, Barton J, Turton A, Howick I. Regulation of the lateral position of body centre of mass in standing balance. Physiother Theory Practice 1992;8:131-5.

13. Adam M, Leblebici B, Erkan AN, Bagis S, Akman MN. Ankylosing Spondylitis and Postural Balance. Arch Rheumatol 2008;23:87-90.

14. Maki BE, Holliday PJ, Topper AK. A prospective study of postural balance and risk of falling in an ambulatory and independent elderly population. J Gerontol 1994;49:72-84.

15. Dursun N, Sarkaya S, Ozdolap S, Dursun E, Zateri C, Altan L, et al. Risk of falls in patients with ankylosing spondylitis. J Clin Rheumatol 2015;21:76-80. 